\title{
Metabolic consequences of acute and chronic empagliflozin administration in treatment-naive and metformin pretreated patients with type 2 diabetes
}

\author{
Elza Muscelli ${ }^{1}$ Brenno Astiarraga ${ }^{1}$ - Elisabetta Barsotti ${ }^{1}$ - Andrea Mari $^{2}$. \\ Freimut Schliess $^{3}$ - Leszek Nosek ${ }^{3}$ • Tim Heise ${ }^{3}$ - Uli C. Broedl ${ }^{4}$. \\ Hans-Juergen Woerle ${ }^{4} \cdot$ Ele Ferrannini $^{1,5}$
}

Received: 22 July 2015 / Accepted: 25 November 2015 / Published online: 24 December 2015

(C) Springer-Verlag Berlin Heidelberg 2015

\begin{abstract}
Aims/hypothesis Sodium glucose co-transporter 2 (SGLT2) inhibitors lower glycaemia by inducing glycosuria, but raise endogenous glucose production (EGP). Metformin lowers glycaemia mainly by suppressing EGP. We compared the effects of the SGLT2 inhibitor empagliflozin in treatment-naive (TN) and metformin pretreated (Met) patients with type 2 diabetes.

Methods A total of $32 \mathrm{TN}$ and 34 patients on a stable dose of metformin, two subgroups of a study that we previously reported, received a mixed meal with double-tracer glucose administration and indirect calorimetry at baseline, after a single $25 \mathrm{mg}$ dose of empagliflozin, and after 4 weeks of treatment with empagliflozin $25 \mathrm{mg} /$ day.

Results At baseline, compared with the TN group, the Met group had higher fasting glycaemia $(9.1 \pm 1.7$ vs 8.2 $\pm 1.3 \mathrm{mmol} / \mathrm{l})$, lower fasting and postmeal insulin secretion, lower beta cell glucose sensitivity (37 [18] vs 58 [43] pmol $\min ^{-1} \mathrm{~m}^{-2}[\mathrm{mmol} / \mathrm{l}]^{-1}$, median [interquartile range]) and
\end{abstract}

Electronic supplementary material The online version of this article (doi:10.1007/s00125-015-3845-8) contains peer-reviewed but unedited supplementary material, which is available to authorised users.

Ele Ferrannini

ferranni@ifc.cnr.it

1 Department of Clinical and Experimental Medicine, University of Pisa, Via Roma, 67, 56100 Pisa, Italy

2 C.N.R. Institute of Neuroscience, Padua, Italy

3 Profil, Neuss, Germany

4 Boehringer Ingelheim Pharma GmbH \& Co. KG, Ingelheim, Germany

5 CNR Institute of Clinical Physiology, Pisa, Italy insulin:glucagon ratio, and higher fasting EGP (15.9 [4.3] vs 12.1 [2.7] $\mathrm{mmol} \mathrm{kg}_{\mathrm{FFM}}{ }^{-1} \mathrm{~min}^{-1}$ ). Change from baseline in fasting EGP after single dose and 4 weeks of treatment with empagliflozin was similar in the Met and TN groups (19.6 [4.2] and 19.0 [2.3] in Met vs 16.2 [3.6] and 15.5 [3.2] $\mu \mathrm{mol} \mathrm{kg} \mathrm{FFM}^{-1} \mathrm{~min}^{-1}$ in $\mathrm{TN}$ for acute and chronic dosing, respectively). Beta cell glucose sensitivity increased less in Met than TN patients, whereas substrate utilisation shifted from carbohydrate to fat more in Met than TN patients.

Conclusions/interpretation At baseline, Met patients with type 2 diabetes had more advanced disease than TN patients, featuring worse beta cell function and higher EGP. Empagliflozin induced similar glycosuria and metabolic and hormonal responses in Met and TN patients.

Trial registration: ClinicalTrials.gov NCT01248364; European Union Clinical Trials Register 2010-018708-99

Keywords Empagliflozin - Endogenous glucose production · Glycosuria $\cdot$ Metformin $\cdot$ Type 2 diabetes
Abbreviations
EGP Endogenous glucose production
FFM Fat-free mass
GLP-1 Glucagon-like peptide-1
GOx Glucose oxidation rate
IQR Interquartile range
LOx Lipid oxidation rate
MCR Metabolic clearance rate of glucose
Met Metformin pretreated
SGLT2 Sodium glucose co-transporter 2
TGD Tissue glucose disposal rate
TN Treatment-naive
UGE Urinary glucose excretion 


\section{Introduction}

Sodium glucose co-transporter 2 (SGLT2) is a low-affinity, highcapacity member of a large family of co-transporters [1] that is highly expressed in the proximal renal tubule where it is responsible for the reabsorption of $\sim 90 \%$ of filtered glucose $[2,3]$. The other $10 \%$ is reabsorbed through the sodium glucose co-transporter 1 in the S3 segment of the proximal tubule. SGLT2 inhibitors have been developed for the treatment of type 2 diabetes and a number are already available for clinical use [4-9]. Other SGLT2 inhibitors and dual SGLT2/SGLT1 inhibitors are being tested for the treatment of type 2 diabetes [10-12].

SGLT2 inhibitors lower fasting and postprandial glycaemia by enhancing urinary glucose excretion (UGE), a mechanism that is independent of insulin secretion [13]. For this reason, SGLT2 inhibitors can be used in association with other antihyperglycaemic agents including dipeptidyl peptidase 4 inhibitors, metformin and insulin [14-16]. In particular, empagliflozin as add-on to metformin has been shown to improve $\mathrm{HbA}_{1 \mathrm{c}}$ and fasting plasma glucose levels for up to 78 weeks [17-19].

Empagliflozin is a potent and selective SGLT2 inhibitor, which decreases plasma glucose and insulin levels and improves beta cell function [20]. The metabolic consequences of acute and chronic empagliflozin administration have been reported [20]. Higher fasting and postmeal rates of endogenous glucose production (EGP) accompanied by changes in the insulin:glucagon ratio and an increase in lipid oxidation have been described following SGLT2 inhibitor monotherapy $[20,21]$. The rise in EGP offsets in part the glucose lost through the urine, thereby blunting the expected decline in glycaemia. The increased EGP can be attributed, at least in part, to the lower insulin and glucose and higher glucagon levels, but other mechanisms cannot be ruled out [22].

Metformin, which is recommended as the first-line oral agent for the treatment of type 2 diabetes [23] lowers glycaemia mainly by decreasing EGP [24]. Therefore, theoretically, metformin has the potential to antagonise the compensatory rise in EGP induced by SGLT2 inhibition. Accordingly, we hypothesised that compensatory increases in EGP might be less pronounced in patients pretreated with metformin and aimed to assess the effects on overall substrate fluxes in patients previously treated with metformin compared with treatment-naive patients. To investigate this, we re-analysed the results of the study reported in reference [20], dividing the patient population into treatment-naive patients and patients pretreated with a stable dose of metformin.

\section{Methods}

Study population Inclusion criteria were type 2 diabetes, age $>18$ years, BMI $20-40 \mathrm{~kg} / \mathrm{m}^{2}$ and $\mathrm{HbA}_{1 \mathrm{c}} 6.5-10.5 \%$
(47.5-91.3 mmol/mol). Patients from a patient population previously reported [20] were required to be treatment-naive (TN) or have been receiving a stable dose of metformin of $\geq 1,500 \mathrm{mg} /$ day for $\geq 3$ months (Met) to be included in the present analysis. Exclusion criteria were as follows: a history of malignancy in the past 5 years; a significant cardiovascular disorder within the past 6 months; pregnancy or expecting to conceive within the study duration; bariatric surgery within the past 2 years; treatment with antiobesity drugs in the past 3 months; impaired renal function defined as an estimated glomerular filtration rate $<60 \mathrm{ml} \mathrm{min}^{-1}(1.73 \mathrm{~m})^{-2}$; neurogenic bladder disorders; alanine and/or aspartate aminotransferase more than three times the upper limit of normal; changes in thyroid hormone dosage within 6 weeks; any other endocrine disease except type 2 diabetes; and alcohol or drug abuse.

The study was carried out at two sites (Pisa, Italy and Neuss, Germany) according to the Declaration of Helsinki and the International Conference on Harmonisation Good Clinical Practice principles. The protocol was approved by the Institutional Review Board at each site. All participants provided informed written consent. The study identifier is ClinicalTrials.gov NCT01248364 (and European Union Clinical Trials Register 2010-018708-99). The results and a detailed description of the methods from the whole study population can be found in [20] and the methods are briefly recapitulated here.

Study design and protocol All patients received empagliflozin in an open-label design. Each participant underwent three studies: baseline, acute study (single dose of empagliflozin $25 \mathrm{mg}$ ) and chronic study (empagliflozin $25 \mathrm{mg}$ /day for 28 days). Each study consisted of a $5 \mathrm{~h}$ meal tolerance test following a $3 \mathrm{~h}$ basal period combined with a double-tracer technique. A primed-constant infusion of $\left[6,6-{ }^{2} \mathrm{H}_{2}\right]$ glucose $\left(0.28 \mu \mathrm{mol} \mathrm{min}^{-1} \mathrm{~kg}^{-1}\right.$; prime $28 \mu \mathrm{mol} \mathrm{kg}{ }^{-1} \times$ [fasting plasma glucose in $\left.\mathrm{mmol} / \mathrm{l}\right] / 5$ ) was administered throughout the test, starting at $-180 \mathrm{~min}$. At time 0 , participants ingested (in $<10 \mathrm{~min}$ ) a meal consisting of one egg, $50 \mathrm{~g}$ of Parmesan cheese, $50 \mathrm{~g}$ of white bread and $75 \mathrm{~g}$ of glucose in water labelled with $1.5 \mathrm{~g}$ of $\left[\mathrm{U}_{-}{ }^{13} \mathrm{C}\right] \mathrm{glucose}$ $(2,970 \mathrm{~kJ}(710 \mathrm{kcal}), 58 \%$ carbohydrate, $24 \%$ fat, $18 \%$ protein). In the acute and chronic studies, empagliflozin was ingested $30 \mathrm{~min}$ before starting tracer infusion (i.e. at time $-210 \mathrm{~min}$ ). During each study, participants drank $500 \mathrm{ml}$ of water at time $-210 \mathrm{~min}$, and were allowed water ad libitum thereafter. Indirect calorimetry was performed for periods of $30 \mathrm{~min}$ at fixed intervals $(-150$ to $-120 \mathrm{~min}$ and -60 to $-0: 30 \mathrm{~min}$ in the fasting state, and from 30 to $60 \mathrm{~min}, 90$ to $120 \mathrm{~min}, 150$ to $180 \mathrm{~min}$ and 270 to $300 \mathrm{~min}$ after meal ingestion). Urine was collected separately during the basal period and during the meal; total volume was recorded for each period and samples were immediately frozen for glucose and urea measurements. 
Measurements All measurements were performed at a central laboratory (Department of Clinical and Experimental Medicine, University of Pisa, Italy). For all analytical determinations, samples from the baseline, acute and chronic study of each participant were assayed together to reduce intraparticipant variability. Tracer enrichments of $\left[6,6-{ }^{2} \mathrm{H}_{2}\right]$ glucose and $\left[\mathrm{U}_{-}{ }^{13} \mathrm{C}\right]$ glucose were measured by GC-MS (Finnigan Trace GC/DSQ, Thermo Electron Corporation, Austin, TX, USA) using electron impact ionisation and selective ion monitoring at mass-to-charge ratios $(\mathrm{m} / \mathrm{e})$ 202/200 and 205/200, respectively [25].

Plasma and urine glucose concentrations were measured by a chemical enzymatic method on a Synchron clinical system CX4 (Beckman Instruments, Fullerton, CA, USA). Plasma insulin and C-peptide were assayed by chemiluminescence (COBAS e411 instrument, Roche, Indianapolis, IN, USA); glucagon was measured by radioimmunoassay and total C-terminal amidated glucagon-like peptide-1 (GLP-1) by ELISA (Millipore Corporation, Billerica, MA, USA). NEFA were measured by a chemical enzymatic method on a Synchron clinical system CX4 (Beckman Instruments).

Calculations Glucose fluxes were expressed per kg of fat-free mass (FFM), which was estimated using the allometric equation of Watson et al [26]. Metabolic clearance rate of glucose (MCR, $\mathrm{ml} \mathrm{min}^{-1} \mathrm{~kg}_{\mathrm{FFM}}{ }^{-1}$ ), rate of appearance of oral glucose and EGP were computed using the circulatory model [27].

The prehepatic insulin:glucagon molar concentration ratio was estimated using the formula described previously [20]. UGE was calculated as the product of urine volume and urine glucose concentration and was subtracted from the rate of total glucose disappearance to obtain tissue glucose disposal rate (TGD). Glucose oxidation rate (GOx), lipid oxidation rate (LOx) and protein oxidation rate were obtained from indirect calorimetry measurements as previously described [28]. Nonoxidative glucose disposal was calculated as the difference between tissue glucose disposal and glucose oxidation (TGD - GOx).

AUCs of concentration-time curves were calculated by the trapezium rule for the $3 \mathrm{~h}$ basal fasting period and the $5 \mathrm{~h}$ postmeal period.

Beta cell function modelling The model used to reconstruct insulin secretion and its control by glucose has been described [29]. In brief, the model consists of three blocks: (1) a model for fitting the glucose concentration profile, the purpose of which is to smooth and interpolate plasma glucose concentrations; (2) a model describing the dependence of insulin (or C-peptide) secretion on glucose concentration; and (3) a model of C-peptide kinetics, i.e. the two-exponential model proposed by Van Cauter et al [30], in which the model variables are individually adjusted to the participant's anthropometric data. The relationship between insulin release and plasma glucose concentrations is modelled as the sum of two components. The first component is the relationship between insulin secretion and glucose concentration, i.e. a dose-response function. The dose-response function is modulated by a time-varying factor, expressing a potentiation effect on insulin secretion. The mean slope of the dose-response function is taken to represent beta cell glucose sensitivity. The second insulin secretion component represents a dynamic dependence of insulin secretion on the rate of change of glucose concentration. This component, termed rate sensitivity, accounts for anticipation of insulin secretion as glucose levels rise. Total insulin secretion is the sum of these two components and is calculated every $5 \mathrm{~min}$ for the whole $5 \mathrm{~h}$ period.

Statistical analysis Data are given as mean \pm SD or median (interquartile range) for normally or non-normally distributed variables, respectively. Group comparisons were tested by ANOVA or Mann-Whitney $U$ test for normally or nonnormally distributed variables, respectively; intragroup acute and chronic treatment responses were analysed by paired $t$ tests or Wilcoxon signed rank tests for normally or nonnormally distributed variables, respectively. Treatment responses were analysed by an ANCOVA model with change from baseline as the outcome variable and baseline values and group as covariates. A $p$ value $\leq 0.05$ was considered statistically significant. All analyses were carried out using JMP 7.0 (www.JMP.com).

\section{Results}

In total, $32 \mathrm{TN}$ patients (21 male patients, $60 \pm 7$ years, BMI $32.3 \pm 4.5 \mathrm{~kg} / \mathrm{m}^{2}$ ) and $34 \mathrm{Met}$ patients (24 male patients, 63 \pm 7 years, BMI $30.9 \pm 4.4 \mathrm{~kg} / \mathrm{m}^{2}$ ) were recruited. Study groups were matched by sex, age and anthropometric measures. More patients in the Met group had a disease duration longer than 10 years, but the difference did not reach statistical significance; fasting glucose levels were significantly higher in the Met group (Table 1). Empagliflozin induced similar glycosuria in the two groups during fasting and after the meal, after both acute and chronic dosing (electronic supplementary material [ESM] Fig. 1).

Metabolic response at fasting During the $3 \mathrm{~h}$ preceding meal ingestion, plasma glucose, insulin and glucagon concentrations dropped similarly in both groups, reflecting progression of the fast. Chronic empagliflozin therapy lowered levels of fasting glucose, insulin and $\mathrm{HbA}_{1 \mathrm{c}}$ to a similar extent in the Met and TN groups (Table 1; Fig. 1). In the baseline study, the time 0 insulin:glucagon ratio was significantly lower in the Met group than in the TN group, mainly due to lower insulin concentrations. This variable decreased in response to acute 
Table 1 Anthropometric variables and metabolic response during fasting

\begin{tabular}{|c|c|c|c|c|c|c|}
\hline \multirow[t]{2}{*}{ Variable } & \multicolumn{3}{|l|}{$\mathrm{TN}$} & \multicolumn{3}{|l|}{ Met } \\
\hline & Baseline & Acute & Chronic & Baseline & Acute & Chronic \\
\hline$n$ (female/male) & $32(11 / 21)$ & $32(11 / 21)$ & $32(11 / 21)$ & $34(10 / 24)$ & $34(10 / 24)$ & $33(10 / 23)$ \\
\hline Age (years) & $60.1 \pm 7.0$ & - & - & $63.3 \pm 6.5$ & - & - \\
\hline Duration of disease $(<1 /<5 /<10 />10$ years $)$ & $(2 / 10 / 15 / 5)$ & - & - & $(1 / 8 / 11 / 14)$ & - & - \\
\hline BMI $\left(\mathrm{kg} / \mathrm{m}^{2}\right)$ & $32.3 \pm 4.5$ & $32.2 \pm 4.5^{* *}$ & $31.8 \pm 4.4^{\dagger}$ & $31.0 \pm 4.7$ & $30.8 \pm 4.6^{\dagger}$ & $30.6 \pm 4.5^{\dagger}$ \\
\hline $\mathrm{HbA}_{1 \mathrm{c}}(\%)$ & $7.1 \pm 0.6$ & $7.1 \pm 0.6$ & $6.7 \pm 0.4^{\dagger}$ & $7.3 \pm 0.8$ & $7.3 \pm 0.7$ & $6.9 \pm 0.6^{\dagger}$ \\
\hline $\mathrm{HbA}_{1 \mathrm{c}}(\mathrm{mmol} / \mathrm{mol})$ & $54 \pm 6$ & $54 \pm 7$ & $50 \pm 5^{\dagger}$ & $56 \pm 8$ & $56 \pm 8$ & $52 \pm 7^{\dagger}$ \\
\hline Estimated glomerular filtration rate $\left(\mathrm{ml} \mathrm{min} \min ^{-1}[1.73 \mathrm{~m}]^{-2}\right)$ & $84 \pm 15$ & $87 \pm 12$ & $85 \pm 13$ & $87 \pm 14$ & $87 \pm 14^{\pi}$ & $82 \pm 14$ \\
\hline \multicolumn{7}{|l|}{ Before drug administration } \\
\hline Fasting plasma glucose $(\mathrm{mmol} / \mathrm{l})$ & $8.2 \pm 1.3$ & $8.4 \pm 1.2$ & $7.2 \pm 0.6^{\dagger}$ & $9.1 \pm 1.7^{\S}$ & $9.3 \pm 1.7$ & $8.0 \pm 1.4^{\dagger}$ \\
\hline Fasting plasma insulin (pmol/l) & $79[44]$ & $82[63]$ & $67[46]^{* *}$ & $72[82]$ & $82[64]$ & $57[54]^{* *}$ \\
\hline Fasting glucagon (pmol/1) & $17 \pm 7$ & $19 \pm 7 *$ & $19 \pm 6$ & $19 \pm 8$ & $20 \pm 7$ & $20 \pm 8^{\pi}$ \\
\hline Fasting insulin:glucagon ratio (mol/mol) & $11[6]$ & $9[4]$ & $8[5]^{\dagger}$ & $8[6]$ & $9[4]$ & $7[4]^{* *}$ \\
\hline \multicolumn{7}{|l|}{ Just before meal ingestion } \\
\hline Time 0 plasma glucose $(\mathrm{mmol} / \mathrm{l})$ & $7.3 \pm 1.0^{*}$ & $6.5 \pm 0.7^{\dagger, *}$ & $6.1 \pm 0.6^{\dagger, \ddagger}$ & $7.5 \pm 1.7^{\S}$ & $6.9 \pm 1.2^{\dagger,+, \pi}$ & $6.4 \pm 1.0^{\dagger, 末}$ \\
\hline Time 0 plasma insulin (pmol/l) & $62[42]^{*}$ & $56[30]^{\ddagger}$ & $51[33]^{* *+*}$ & $56[54]^{\S}$ & $49[33]^{*, *}$ & $34[49]^{\dagger,+, \pi}$ \\
\hline Time 0 glucagon (pmol/l) & $15 \pm 6^{\ddagger}$ & $18 \pm 8 * *$ & $16 \pm 5^{\ddagger}$ & $17 \pm 5^{\S}$ & $19 \pm 7 * *$ & $18 \pm 7^{\ddagger}$ \\
\hline Time 0 insulin:glucagon ratio $(\mathrm{mol} / \mathrm{mol})$ & $11[7]$ & $9[5]^{\dagger+末}$ & $7[4]^{\dagger}$ & $8[4]^{\S}$ & $6[3]^{* *,+}$ & $6[3]^{* * *}$ \\
\hline
\end{tabular}

Data are mean $\pm \mathrm{SD}$ or median [interquartile range] for normally and non-normally distributed variables, respectively

${ }^{\dagger} p<0.0001,{ }^{*} p<0.01,{ }^{*} p<0.05$ for acute or chronic vs corresponding baseline value

${ }^{\star} p<0.05$ for time 0 vs fasting

$\S_{p} \leq 0.05$ for TN vs Met patients at baseline

ๆ Significant baseline-adjusted difference $(p \leq 0.05)$ for between-group changes

and chronic empagliflozin dosing similarly in the two groups (Table 1).

Postmeal metabolic response In the baseline study, plasma glucose excursions peaked at $90 \mathrm{~min}$ and did not return to fasting values before $5 \mathrm{~h}$, with similar values and time course in the Met and TN groups (Fig. 1). In both groups, acute and chronic empagliflozin dosing reduced the plasma glucose response by $\sim 12 \%$ (Table 2 ). The baseline postmeal insulin response was lower and the glucagon response tended to be higher $(p=0.056)$ in the Met group, such that the prehepatic insulin:glucagon molar concentration ratio was half that of the TN group; acute and chronic empagliflozin dosing significantly reduced this ratio in both groups. The baseline postmeal GLP-1 and NEFA responses were higher in the Met than the $\mathrm{TN}$ group, and rose similarly with acute and chronic treatment (Table 2).

In the baseline study, fasting and postmeal insulin release was significantly lower in the Met group than the TN group, and tended to decline following empagliflozin administration in both groups (Table 3, Fig. 2). When insulin secretion rates were analysed in the context of concomitant plasma glucose concentrations, model-derived beta cell glucose sensitivity was markedly depressed in the Met group as compared with the TN group at baseline. With empagliflozin, beta cell glucose sensitivity improved (Fig. 2), but in the Met group it remained significantly more impaired than in the $\mathrm{TN}$ group. Empagliflozin treatment was not associated with changes in rate sensitivity or potentiation in either group.

Endogenous glucose production At baseline, fasting EGP was significantly higher in Met than TN patients (Table 4). Incremental changes in fasting EGP were not significantly different between the Met and TN groups (Table 4). Following the meal, EGP $\mathrm{AUC}_{\mathrm{A}}$ was higher after acute empagliflozin administration as compared with baseline in both Met and TN patients and remained higher after chronic dosing in Met patients (Fig. 3). Rates of appearance of oral glucose were similar across study and group. By contrast, TGD was reduced with empagliflozin in both groups, whilst MCR was significantly improved acutely and chronically to a similar extent in both groups (ESM Table 1).

With regard to substrate utilisation, postmeal rates of GOx and LOx were similar at baseline in both groups, and in both groups, chronic (but not acute) empagliflozin treatment was associated with a decrement in GOx and an increase in LOx. 
Fig. 1 (a, b) Plasma glucose, $(\mathbf{c}, \mathbf{d})$ insulin concentrations and $(\mathbf{e}, \mathbf{f})$ estimated prehepatic insulin:glucagon molar concentration ratio in $\mathrm{TN}(\mathbf{a}, \mathbf{c}, \mathbf{e})$ and Met patients $(\mathbf{b}, \mathbf{d}, \mathbf{f})$ with type 2 diabetes at baseline (blue lines), after a single dose of empagliflozin (red lines) and following 4 weeks of empagliflozin administration (green lines) during $3 \mathrm{~h}$ of fasting and $5 \mathrm{~h}$ after mixed meal ingestion a
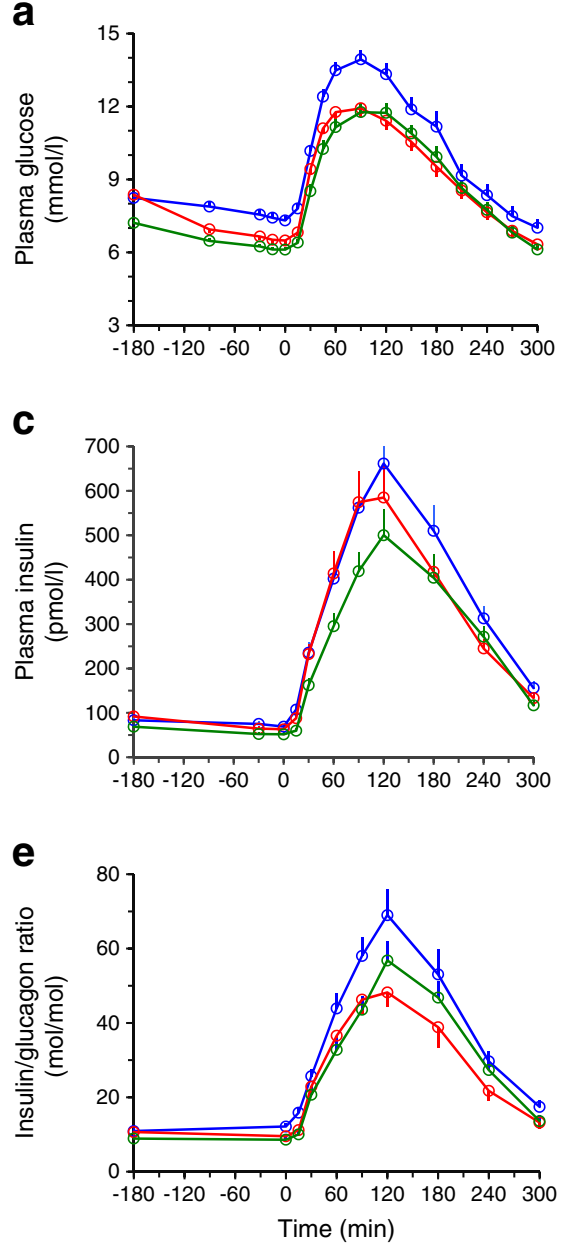

b

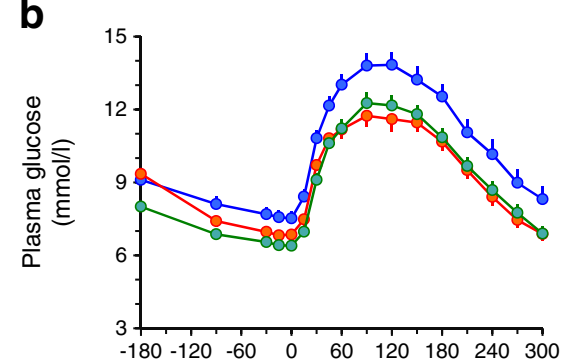

d

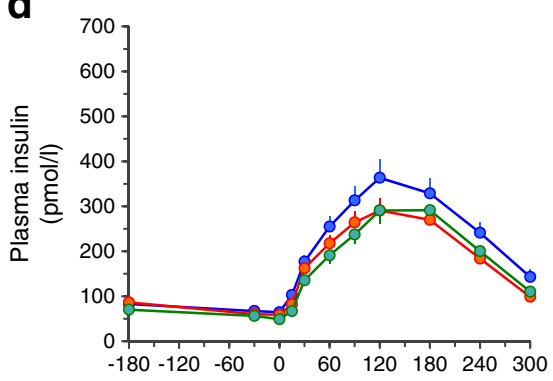

f

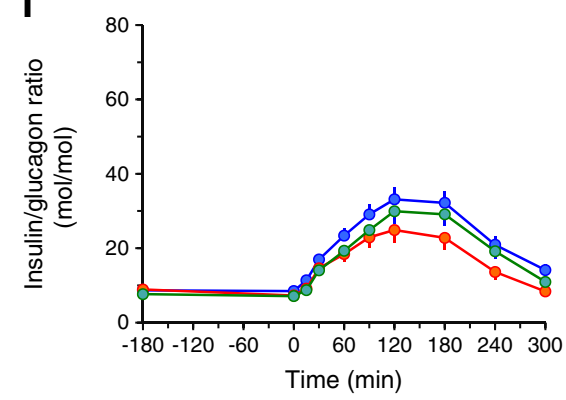

However, in Met patients, the decrease in GOx and increase in LOx were significantly larger than in TN patients (ESM Table 1).
In an attempt to analyse responses in Met vs $\mathrm{TN}$ under comparable baseline conditions, we selected 15 patients from each group who were adequately matched for both baseline

Table 2 Postmeal metabolic response

\begin{tabular}{|c|c|c|c|c|c|c|}
\hline \multirow[t]{2}{*}{ Variable } & \multicolumn{3}{|l|}{$\mathrm{TN}$} & \multicolumn{3}{|l|}{ Met } \\
\hline & Baseline & Acute & Chronic & Baseline & Acute & Chronic \\
\hline $\mathrm{AUC}_{\mathrm{G}}(\mathrm{g} / \mathrm{dl} \times \mathrm{h})$ & $54[16]$ & $49[9]^{\dagger}$ & $49[8]^{\dagger}$ & $58[15]$ & $51[12]^{\dagger}$ & $52[12]^{\dagger}$ \\
\hline $\mathrm{AUC}_{\mathrm{I}}(\mathrm{nmol} / \mathrm{l} \times \mathrm{h})$ & $112[74]$ & $105[56]^{* *}$ & $88[53]^{\dagger}$ & $71[55]^{\S}$ & $57[40]^{\dagger, \pi}$ & $57[51]^{\dagger}$ \\
\hline $\mathrm{AUC}_{\mathrm{Glg}}(\mathrm{nmol} / 1 \times \mathrm{h})$ & $4.92 \pm 1.44$ & $6.22 \pm 2.18^{\dagger}$ & $5.30 \pm 1.49^{* *}$ & $5.71 \pm 1.69$ & $7.02 \pm 2.03^{\dagger}$ & $6.15 \pm 1.99 *$ \\
\hline Meal insulin:glucagon ratio (mol/mol) & $35[25]$ & $28[12]^{\dagger}$ & $30[14]^{\dagger}$ & $18[18]^{\S}$ & $15[14]^{\dagger}$ & $18[13]^{* *}$ \\
\hline $\mathrm{AUC}_{\mathrm{GLP}-1}(\mathrm{nmol} / \mathrm{l} \times \mathrm{h})$ & $7.0 \pm 2.4$ & $8.9 \pm 3.1^{\dagger}$ & $7.7 \pm 2.9$ & $9.5 \pm 3.1^{\S}$ & $11.8 \pm 4.1^{\dagger}$ & $10.5 \pm 4.2 *$ \\
\hline $\mathrm{AUC}_{\mathrm{GIP}}(\mathrm{nmol} / \mathrm{l} \times \mathrm{h})$ & $45.3 \pm 54.6$ & $48.5 \pm 62.3$ & $43.7 \pm 61.4$ & $32.1 \pm 10.3$ & $32.2 \pm 10.3$ & $30.0 \pm 9.3 *$ \\
\hline $\operatorname{AUC}_{\mathrm{FFA}}(\mathrm{mmol} / \mathrm{l} \times \mathrm{h})$ & $61 \pm 21$ & $77 \pm 23^{\dagger}$ & $90 \pm 31^{\dagger}$ & $73 \pm 24^{\S}$ & $94 \pm 32^{\dagger}$ & $99 \pm 35^{\dagger}$ \\
\hline
\end{tabular}

Data are mean $\pm \mathrm{SD}$ or median [interquartile range] for normally and non-normally distributed variables, respectively

$\S_{p}<0.05$ for the comparison of TN and Met patients at baseline

${ }^{\dagger} p<0.0001, * * p<0.01, * p<0.05$ for the paired comparison between baseline and acute or chronic study

" Significant baseline-adjusted difference $(p \leq 0.05)$ for between-group changes

$\mathrm{AUC}_{\mathrm{G}}, \mathrm{AUC}$ glucose; $\mathrm{AUC}_{\mathrm{GIP}}$, AUC gastric inhibitory polypeptide; $\mathrm{AUC}_{\mathrm{Glg}}$, $\mathrm{AUC}$ glucagon; $\mathrm{AUC}$, $\mathrm{AUC}$ insulin 
Table 3 Beta cell function variables during the meal

\begin{tabular}{|c|c|c|c|c|c|c|}
\hline \multirow[t]{2}{*}{ Variable } & \multicolumn{3}{|l|}{$\mathrm{TN}$} & \multicolumn{3}{|l|}{ Met } \\
\hline & Baseline & Acute & Chronic & Baseline & Acute & Chronic \\
\hline Fasting ISR (pmol $\min ^{-1} \mathrm{~m}^{-2}$ ) & $134[46]$ & $117[44]$ & $103[39]^{\dagger}$ & $107[55]^{\S}$ & $110[55]$ & $100[46]^{* *}$ \\
\hline Total IS $\left(\mathrm{nmol} \mathrm{m}^{-2}\right)$ & $124[44]$ & $118[47]$ & $118[42]$ & $93[27]^{\S}$ & $88[31]^{*}$ & $86[33]$ \\
\hline Beta GS (pmol $\min ^{-1} \mathrm{~m}^{-2}[\mathrm{mmol} / \mathrm{l}]^{-1}$ ) & $58[43]$ & $72[57]^{\dagger}$ & $77[38]^{* *}$ & $37[18]^{\S}$ & $46[28]^{* *, \pi}$ & $45[29]^{\pi}$ \\
\hline Potentiation factor (ratio) & $1.19[0.24]$ & $1.18[0.36]$ & $1.07[0.21]$ & $1.06[0.29]$ & $1.05[0.29]$ & $1.06[0.22]$ \\
\hline Rate sensitivity $\left(\mathrm{pmol} \mathrm{m}{ }^{-2}[\mathrm{mmol} / \mathrm{l}]^{-1}\right)$ & $206[591]$ & $241[435]$ & $272[436]$ & $146[629]$ & $124[365]$ & $154[288]$ \\
\hline
\end{tabular}

Data are median [interquartile range]

$\S_{p}<0.05$ for the comparison of TN and Met patients at baseline

${ }^{\dagger} p<0.0001,{ }^{* *} p<0.01,{ }^{*} p<0.05$ for the paired comparison between baseline and acute or chronic study

" Significant baseline-adjusted difference $(p \leq 0.05)$ for between-group changes

ISR, insulin secretion rate; IS, insulin secretion; Beta GS, beta cell glucose sensitivity

beta cell glucose sensitivity (42 [30] vs 46 [36] pmol $\min ^{-1} \mathrm{~m}^{-2}[\mathrm{mmol} / 1]^{-1}$, respectively, $\left.p=0.95\right)$ and baseline fasting EGP (13.9 [2.3] vs 12.4 [3.2] $\mathrm{mol} \mathrm{kg}_{\mathrm{FFM}}{ }^{-1} \mathrm{~min}^{-1}$, $p=0.45$ ). In this Met subgroup, fasting EGP still rose (by 3.4 [2.7] and 3.5 [3.1] $\mu \mathrm{mol} \mathrm{kg}_{\mathrm{FFM}}{ }^{-1} \mathrm{~min}^{-1}$ with acute and chronic empagliflozin dosing, respectively) in a similar degree as in the matched TN subgroup (3.3 [2.2] and 2.0 [3.2] $\mu \mathrm{mol}$ $\mathrm{kg}_{\mathrm{FFM}}{ }^{-1} \mathrm{~min}^{-1}$ ). Alongside this increase, the glucagon response was still stimulated (from $6.21 \pm 1.75$ to $7.82 \pm 1.68 \mathrm{nmol}^{-1} \mathrm{~h}$ in the Met subgroup) and beta cell glucose sensitivity failed to rise to the same extent as in the TN subgroup (from 42 [30] to $53[24] \mathrm{pmol} \mathrm{min}^{-1} \mathrm{~m}^{-2}[\mathrm{mmol} / 1]^{-1}$ in the Met subgroup vs 46

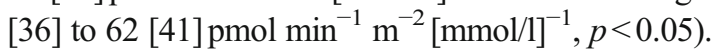

\section{Discussion}

In this study, we compared the metabolic consequences of empagliflozin in TN and Met patients with type 2 diabetes. We found that compensatory increases in EGP following acute (single dose) or chronic (28 days) treatment with empagliflozin were similar in both patient groups. As one of the main actions of metformin is to suppress EGP (24), one might speculate that the effect of empagliflozin on increasing EGP would be blunted or abolished by metformin. While this may be the case if the two drugs are started together, it was not the case in Met patients who were then treated with empagliflozin. Fasting EGP was higher in the Met patients than the TN patients at baseline and after acute and chronic
Fig. 2 Insulin secretion rate in TN (a) and Met patients (b) with type 2 diabetes at baseline (blue lines), after a single dose of empagliflozin (red lines), and following 4 weeks of empagliflozin administration (green lines) during $3 \mathrm{~h}$ of fasting and $5 \mathrm{~h}$ after mixed meal ingestion. The data in (a) and (b) are plotted against the corresponding plasma glucose concentrations (see Fig. 1) in (c) and (d); the mean slopes of the fitting lines measure beta cell glucose sensitivity
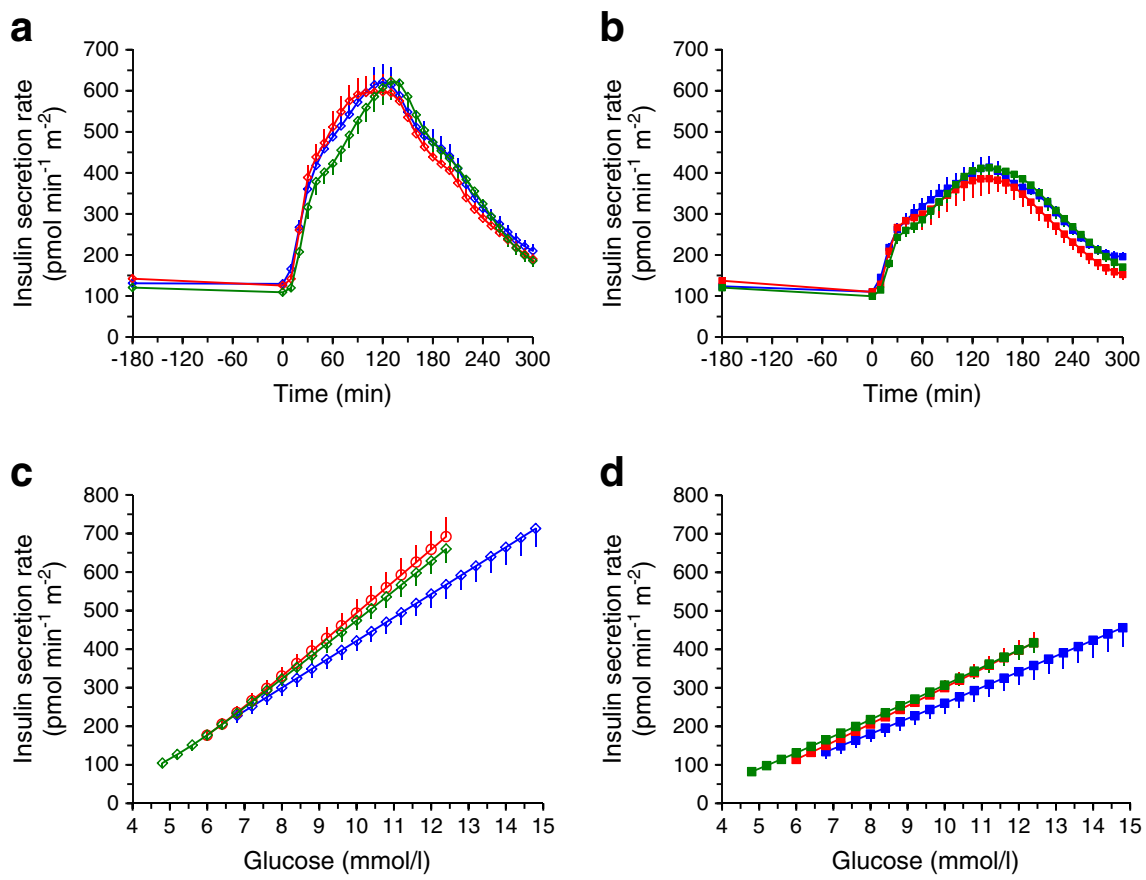
Table 4 EGP in the fasting state and during the meal

\begin{tabular}{|c|c|c|c|c|c|c|}
\hline \multirow[t]{2}{*}{ Variable } & \multicolumn{3}{|l|}{$\mathrm{TN}$} & \multicolumn{3}{|l|}{ Met } \\
\hline & Baseline & Acute & Chronic & Baseline & Acute & Chronic \\
\hline Fasting EGP $\left(\mu \mathrm{mol} \mathrm{kg} \mathrm{FFM}^{-1} \min ^{-1}\right)$ & $12.1[2.7]$ & $16.2[3.6]^{\dagger}$ & $15.5[3.2]^{\dagger}$ & $15.9[4.3]^{\S}$ & $19.6[4.2]^{\dagger}$ & $19.0[2.3]^{\dagger}$ \\
\hline $\mathrm{EGP}_{\mathrm{AUC}}(\mathrm{g})$ & $37[13]$ & $37[15]^{*}$ & 35 [12] & $34[10]$ & $40[13]^{\dagger}$ & $38[12]^{* *}$ \\
\hline $\operatorname{EGP}_{\mathrm{AUC}}\left(\mathrm{mmol} / \mathrm{kg}_{\mathrm{FFM}} \times \mathrm{h}\right)$ & $3.03[1.35]$ & $3.72[1.18]^{*}$ & $3.35[0.86]$ & $3.10[1.15]$ & $3.55[1.84]^{\dagger, \pi}$ & $3.52[1.01]^{* *}$ \\
\hline
\end{tabular}

Data are median [interquartile range]

${ }^{\dagger} p<0.0001,{ }^{* *} p<0.01,{ }^{*} p<0.05$ for the paired comparison between baseline and acute or chronic study

$\S_{p}<0.05$ for the comparison of TN and Met patients at baseline

ๆ Significant baseline-adjusted difference $(p \leq 0.05)$ for between-group changes

empagliflozin treatment, presumably because the patients on background metformin had more severe diabetes, as shown by more impaired beta cell glucose sensitivity and a lower insulin:glucagon ratio. GLP-1 secretion was more pronounced in the Met group than the TN group, consistent with previous observations that metformin stimulates meal-dependent GLP1 release [31, 32]. In subgroup analyses of Met and TN patients matched for baseline beta cell function and fasting EGP, metformin background medication failed to abolish the empagliflozin-induced rise in EGP, suggesting that other aspects of the disease in metformin-treated patients contribute to maintain the effect of SGLT2 inhibition on EGP.

In both Met and TN patients, administration of empagliflozin, whether by single dosing or more protracted treatment, improved metabolic control through a significant increase in glycosuria. The overall metabolic response to glycosuria included reductions in plasma glucose and insulin levels, increases in glucagon and GLP-1 concentrations,
Fig. 3 Rates of oral glucose appearance and EGP in TN $(\mathbf{a}, \mathbf{c})$ and Met patients $(\mathbf{b}, \mathbf{d})$ with type 2 diabetes at baseline (blue lines), after a single dose (acute study, red lines) and after 4 weeks of empagliflozin administration (chronic study, green lines). (e, f) Point-by-point difference in EGP between the acute (red line) or chronic (green line) study and the baseline study in patients with type 2 diabetes
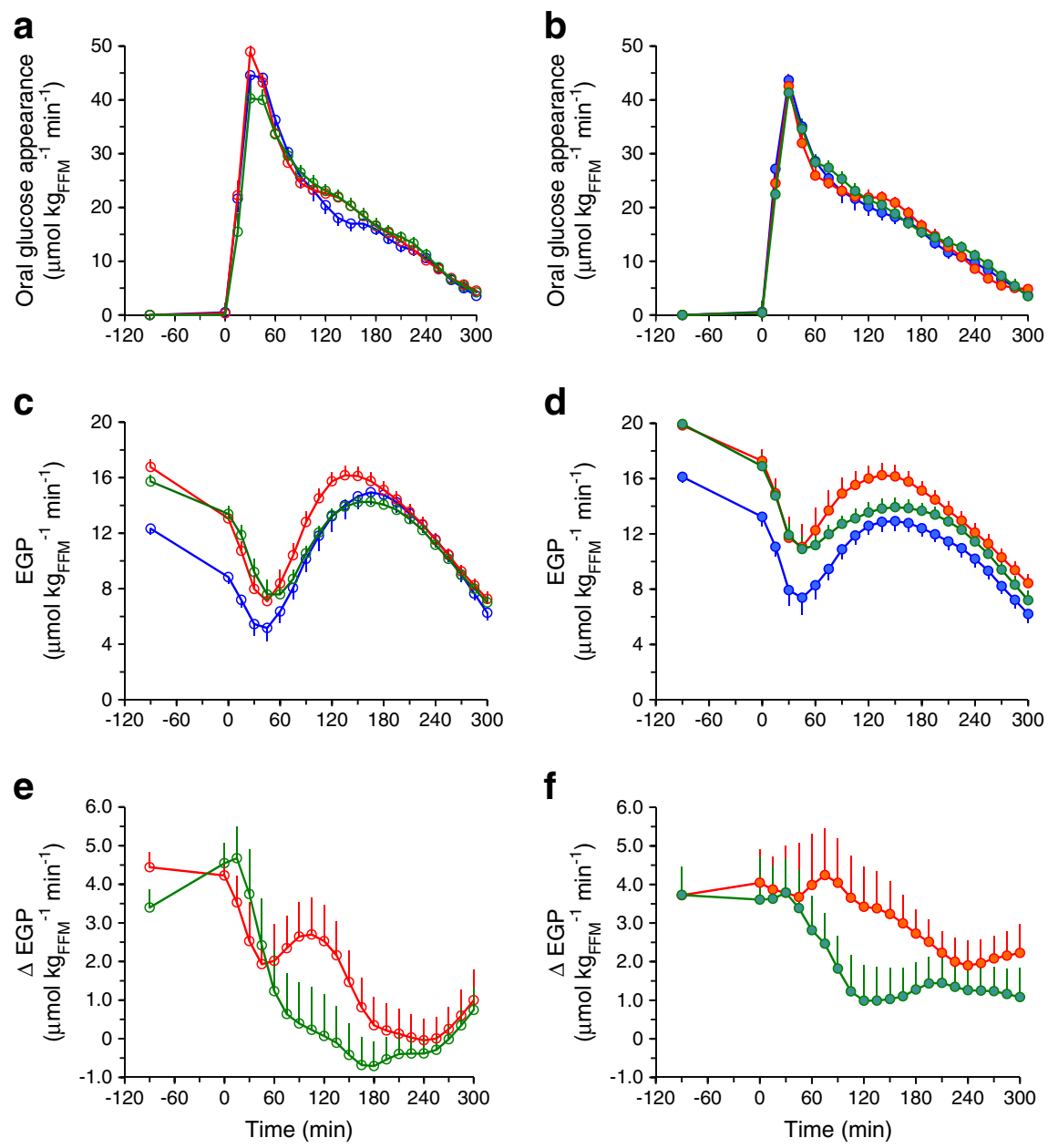

f

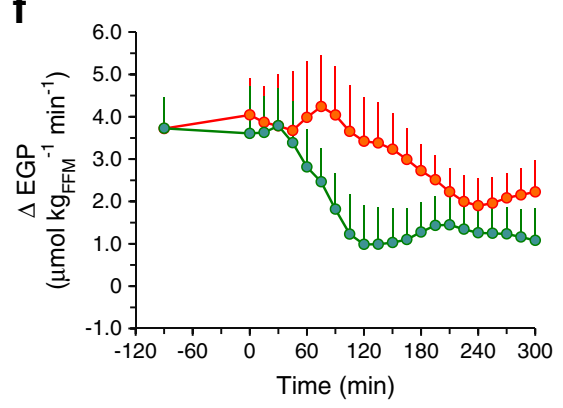


increments in EGP and decreases in TGD; with chronic administration, whole-body substrate utilisation shifted from carbohydrate to fat, as shown by a reduced suppression of circulating NEFA and increases in LOx. These changes were accompanied by rapid improvements in beta cell function and metabolic glucose clearance. Thus, both the Met and TN patients reproduced the complex metabolic adaptation to pharmacologically induced glycosuria that was observed in this cohort as a whole [20] and has also been reported for other members of the SGLT2 inhibitor class [21]. The compensatory increase in EGP that occurs with empagliflozin treatment may attenuate the reduction in hyperglycaemia that would be predicted from the increase in UGE, although increases in food intake may also contribute [33]. The observed shift in substrate oxidation from carbohydrate to fat is consistent with the weight loss that has been observed in clinical trials of empagliflozin [14]. The hormonal changes, increased lipolysis and fat oxidation are the metabolic background for the increase in ketone bodies described in a small number of patients receiving SGLT2 inhibitor therapy [34].

In summary, in this study of the metabolic consequences of empagliflozin in patients with type 2 diabetes, Met patients had more advanced disease than TN patients, as illustrated by worse beta cell function and higher EGP; however, empagliflozin induced similar glycosuria and metabolic and hormonal responses in both patient groups.

Acknowledgements Medical writing assistance, supported financially by Boehringer Ingelheim, was provided by W. Morris of FleishmanHillard Group Ltd, during the preparation of this manuscript. The authors were fully responsible for all content and editorial decisions, were involved at all stages of manuscript development and approved the final version. The authors thank the patients and staff who participated in this study.

Funding The study was funded through a research grant from Boehringer Ingelheim and Eli Lilly and Company.

Duality of interest EM has received grants from Boehringer Ingelheim. TH is a consultant of Novo Nordisk, has received speaker honoraria from Eli Lilly and Company, Mylan and Novo Nordisk and has received research grants from Adocia, AstraZeneca, Becton Dickinson, Biocon, Boehringer Ingelheim, Dance Pharmaceuticals, Grünenthal, Eli Lilly and Company, Medtronic, Novo Nordisk, Novartis, Sanofi and Senseonics. UCB and HJW are employees of Boehringer Ingelheim. EF is a consultant of Merck Sharp \& Dohme, Sanofi, Boehringer Ingelheim, Eli Lilly and Company and Janssen, and has received research grants from Boehringer Ingelheim and Eli Lilly and Company. All other authors declare that there is no duality of interest associated with their contribution to this manuscript.

Contribution statement EM participated in the conduct of the study, the collection of data, the analysis and interpretation of the results and drafted the manuscript. FS, LN and TH participated in the collection of data and revision of the manuscript. BA, EB and AM contributed to the collection of data and revision of the manuscript. UCB and HJW participated in the design of the study, interpretation of the results and revision of the manuscript. EF was responsible for the design and conduct of the study and the analysis and interpretation of the results and revised the manuscript. All authors approved the final version of this manuscript. EF is the guarantor of this work.

\section{References}

1. Wright EM, Loo DD, Hirayama BA (2011) Biology of human sodium glucose transporters. Physiol Rev 91:733-794

2. Hummel CS, Lu C, Loo DD, Hirayama BA, Voss AA, Wright EM (2011) Glucose transport by human renal Na+/D-glucose cotransporters SGLT1 and SGLT2. Am J Physiol Cell Physiol 300:C14-C21

3. Vallon V, Platt KA, Cunard R et al (2011) SGLT2 mediates glucose reabsorption in the early proximal tubule. J Am Soc Nephrol 22: 104-112

4. Boehringer Ingelheim International GmbH (2015). Jardiance (empagliflozin). Summary of product characteristics. Available from www.ema.europa.eu/docs/en GB/document library/EPAR Product Information/human/002677/WC500168592.pdf. $\overline{\text { Accessed }} \mathbf{2} 7$ Apr 2015

5. AstraZeneca AB (2015). Forxiga (dapagliflozin). Summary of product characteristics. Available from www.ema.europa.eu/docs/ en_GB/document_library/EPAR__Product_Information/human/ 002322/WC500136026.pdf. Accessed 27 Apr 2015

6. Janssen-Cilag International NV (2015). Invokana (canagliflozin). Summary of product characteristics. Available from www.ema. europa.eu/docs/en_GB/document_library/EPAR__Product Information/human/002649/WC500156456.pdf. Accessed $2 \overline{7}$ Apr 2015

7. Poole RM, Dungo RT (2014) Ipragliflozin: first global approval. Drugs 74:611-617

8. Poole RM, Prossler JE (2014) Tofogliflozin: first global approval. Drugs 74:939-944

9. Markham A, Elkinson S (2014) Luseogliflozin: first global approval. Drugs $74: 945-950$

10. Zambrowicz B, Freiman J, Brown PM et al (2012) LX4211, a dual SGLT1/SGLT2 inhibitor, improved glycemic control in patients with type 2 diabetes in a randomized, placebo-controlled trial. Clin Pharmacol Ther 92:158-169

11. Amin NB, Wang X, Jain SM, Lee DS, Nucci G, Rusnak JM (2015) Dose-ranging efficacy and safety study of ertugliflozin, a sodiumglucose co-transporter 2 inhibitor, in patients with type 2 diabetes on a background of metformin. Diabetes Obes Metab 17:591-598

12. Sykes AP, Kemp GL, Dobbins R et al (2015) Randomized efficacy and safety trial of once-daily remogliflozin etabonate for the treatment of type 2 diabetes. Diabetes Obes Metab 17:98-101

13. Ferrannini E, Solini A (2012) SGLT2 inhibition in diabetes mellitus: rationale and clinical prospects. Nat Rev Endocrinol 8: 495-502

14. Liakos A, Karagiannis T, Athanasiadou E et al (2014) Efficacy and safety of empagliflozin for type 2 diabetes: a systematic review and meta-analysis. Diabetes Obes Metab 16:984-993

15. Liakos A, Karagiannis T, Bekiari E, Boura P, Tsapas A (2015) Update on long-term efficacy and safety of dapagliflozin in patients with type 2 diabetes mellitus. Ther Adv Endocrinol Metab 6:61-67

16. Plosker G (2014) Canagliflozin: a review of its use in patients with type 2 diabetes mellitus. Drugs 74:807-824

17. Rosenstock J, Seman LJ, Jelaska A et al (2013) Efficacy and safety of empagliflozin, a sodium glucose cotransporter 2 (SGLT2) inhibitor, as add-on to metformin in type 2 diabetes with mild hyperglycaemia. Diabetes Obes Metab 15:1154-1160 
18. Ferrannini E, Berk A, Hantel S et al (2013) Long-term safety and efficacy of empagliflozin, sitagliptin, and metformin: an active-controlled, parallel-group, randomized, 78-week open-label extension study in patients with type 2 diabetes. Diabetes Care 36:4015-4021

19. Häring HU, Merker L, Seewaldt-Becker E et al (2014) Empagliflozin as add-on to metformin in patients with type 2 diabetes: a 24-week, randomized, double-blind, placebo-controlled trial. Diabetes Care 37:1650-1659

20. Ferrannini E, Muscelli E, Frascerra S et al (2014) Metabolic response to sodium-glucose co-transporter-2 inhibition in type 2 diabetic patients. J Clin Invest 124:499-508

21. Merovci A, Solis-Herrera C, Daniele G et al (2014) Dapagliflozin improves muscle insulin sensitivity but enhances endogenous glucose production. J Clin Invest 124:509-514

22. Mutel E, Gautier-Stein A, Abdul-Wahed A et al (2011) Control of blood glucose in the absence of hepatic glucose production during prolonged fasting in mice: induction of renal and intestinal gluconeogenesis by glucagon. Diabetes 60:3121-3131

23. Inzucchi SE, Bergenstal RM, Buse JB et al (2015) Management of hyperglycaemia in type 2 diabetes, 2015: a patient-centred approach. Update to a position statement of the American Diabetes Association and the European Association for the Study of Diabetes. Diabetologia 58:429-442

24. Ferrannini E (2014) The target of metformin in type 2 diabetes. N Engl J Med 371:1547-1548

25. Gastaldelli A, Casolaro A, Pettiti M et al (2007) Effect of pioglitazone on the metabolic and hormonal response to a mixed meal in type II diabetes. Clin Pharmacol Ther 81:205-212

26. Watson PE, Watson ID, Batt RD (1980) Total body water volumes for adult males and females estimated from simple anthropometric measurements. Am J Clin Nutr 33:27-39
27. Mari A, Stojanovska L, Proietto J, Thorburn AW (2003) A circulatory model for calculating non-steady-state glucose fluxes. Validation and comparison with compartmental models. Comput Methods Prog Biomed 71:269-281

28. Ferrannini E (1988) The theoretical bases of indirect calorimetry: a review. Metabolism 37:287-301

29. Mari A, Schmitz O, Gastaldelli A, Oestergaard T, Nyholm B, Ferrannini E (2002) Meal and oral glucose tests for assessment of $\beta$-cell action: modelling analysis in normal subjects. Am J Physiol Endocrinol Metab 283:E1159-E1166

30. Van Cauter E, Mestrez F, Sturis J, Polonsky KS (1992) Estimation of insulin secretion rates from C-peptide levels: comparison of individual and standard kinetic parameters for C-peptide clearance. Diabetes 41:368-377

31. Wu T, Thazhath SS, Bound MJ, Jones KL, Horowitz M, Rayner CK (2014) Mechanism of increase in plasma intact GLP-1 by metformin in type 2 diabetes: stimulation of GLP-1 secretion or reduction in plasma DPP-4 activity? Diabetes Res Clin Pract 106:e3-e6

32. Cuthbertson J, Patterson S, O'Harte FP, Bell PM (2011) Addition of metformin to exogenous glucagon-like peptide-1 results in increased serum glucagon-like peptide- 1 concentrations and greater glucose lowering in type 2 diabetes mellitus. Metabolism 60:52-56

33. Ferrannini G, Hach T, Crowe S, Sanghvi A, Hall KD, Ferrannini E (2015) Energy balance following sodium-glucose co-transporter-2 (SGLT2) inhibition. Diabetes Care 38:1730-1735

34. Peters AL, Buschur EO, Buse JB et al (2015) Euglycemic diabetic ketoacidosis: a potential complication of treatment with sodiumglucose cotransporter 2 inhibition. Diabetes Care 38:1687-1693 